University of Nebraska - Lincoln DigitalCommons@University of Nebraska - Lincoln

US Army Corps of Engineers

U.S. Department of Defense

1998

\title{
Subsurface Heavy-Metal Detection with the use of a Laser-Induced Breakdown Spectroscopy (LIBS) Penetrometer System
}

Brian Miles

U.S. Army Engineer Waterways Experiment Station

Javier Cortes

U.S. Army Engineer Waterways Experiment Station

Follow this and additional works at: http://digitalcommons.unl.edu/usarmyceomaha

Part of the Earth Sciences Commons, Environmental Sciences Commons, and the Oceanography and Atmospheric Sciences and Meteorology Commons

Miles, Brian and Cortes, Javier, "Subsurface Heavy-Metal Detection with the use of a Laser-Induced Breakdown Spectroscopy (LIBS) Penetrometer System" (1998). US Army Corps of Engineers. 167.

http://digitalcommons.unl.edu/usarmyceomaha/167

This Article is brought to you for free and open access by the U.S. Department of Defense at DigitalCommons@University of Nebraska - Lincoln. It has been accepted for inclusion in US Army Corps of Engineers by an authorized administrator of DigitalCommons@University of Nebraska - Lincoln. 


\title{
Subsurface Heavy-Metal Detection with the use of a Laser-Induced Breakdown Spectroscopy (LIBS) Penetrometer System
}

\author{
Brian Miles and Javier Cortes \\ U.S. Army Engineer Waterways Experiment Station, Vicksburg, Mississippi 39180
}

Received 3 November 1997; revised 9 December 1997; accepted 26 December 1997

\begin{abstract}
U.S. Army Engineer Waterways Experiment Station (WES) investigators have designed, fabricated, and demonstrated a cone penetrometer sensor for subsurface in situ field screening based on LIBS. The LIBS probe (patent pending) presented here is one of a suite of contaminant and geophysical probes developed by the WES Site Characterization and Analysis Penetrometer System (SCAPS) program. The LIBS probe includes a laser as part of the optical LIBS sensor section for metals analysis and a cone and sleeve soil classification module at its tip. Soil classification data are acquired during the push, while LIBS data are recorded during probe retraction, after shedding a sacrificial sleeve. Optical design concerns are discussed including the recessed window geometry to avoid output window damage and associated problems. Calibration, peak identification and peak confidence software are discussed. Although producing lower signal strength, the nonimaging optical receiver utilized is based on a simple design. Its performance is less dependent on soil conditions and produces a more consistent optical signal when compared to an imaging optical receiver design. Field results from four sites are discussed. Some spectral samples from a site indicate contaminant material that is not mixed with soil, as evidenced by spectra with a total lack of characteristic iron peaks in the background. Soil grain size and soil moisture are discussed in the context of empirical calibration and their effect on LIBS measurements. (c)1998 John Wiley \& Sons, Inc. Field Analyt Chem Technol 2: 75-87, 1998
\end{abstract}

Keywords: laser-induced breakdown spectroscopy (LIBS); heavy metals; site screening; cone penetrometer; site characterization and analysis penetrometer system (SCAPS).

Correspondence to: $\mathrm{B}$. Miles

Contract grant sponsor: Strategic Environmental Research and Development Program

(C) 1998 by John Wiley \& Sons, Inc.

\section{Introduction}

\section{Heavy Metal Contamination}

The U.S. Army Engineer Waterways Experiment Station (WES), under the sponsorship of the Strategic Environmental Research and Development Program (SERDP), has developed LIBS technology to address critical environmental concerns raised as a result of past Department of Defense (DoD) operations. Many DoD operations have produced heavy metals waste as a part of an industrial process or training exercise. Often chromium, cadmium, nickel, and zinc were introduced into the soil at DoD sites via plating activities. Lead was introduced into soils at outdoor small arms firing ranges, many of which utilize earthen impact berms to stop the bullets. Many ranges, present since World War II, have impact berms laden with tens of thousands of rounds. Lead-based paints were previously used in and on DoD structures and vehicles. In the past, when a vehicle's paint was stripped it was often not treated as hazardous waste and was simply left on site.

The DoD is responsible for cleanup of sites where military activities produced contamination. Site characterization is the first phase of the cleanup process. Unfortunately, often very little is known about the subsurface bounds of the contamination. In some cases site history can yield information on the type of metal contaminant and spill or waste lagoon locations, but seldom can site history yield information on the extent of the subsurface contamination or its concentration. In more difficult cases neither the contaminant nor the spill location are known precisely and thus must be determined somehow.

Traditionally, characterization of potential hazardous waste sites requires drilling to obtain core samples and subsequent placement of monitoring wells. Both water and soil samples must often be taken off site to a laboratory for further sample preparation and analysis. This process is slow and costly and, consequently, often yields a limited picture 


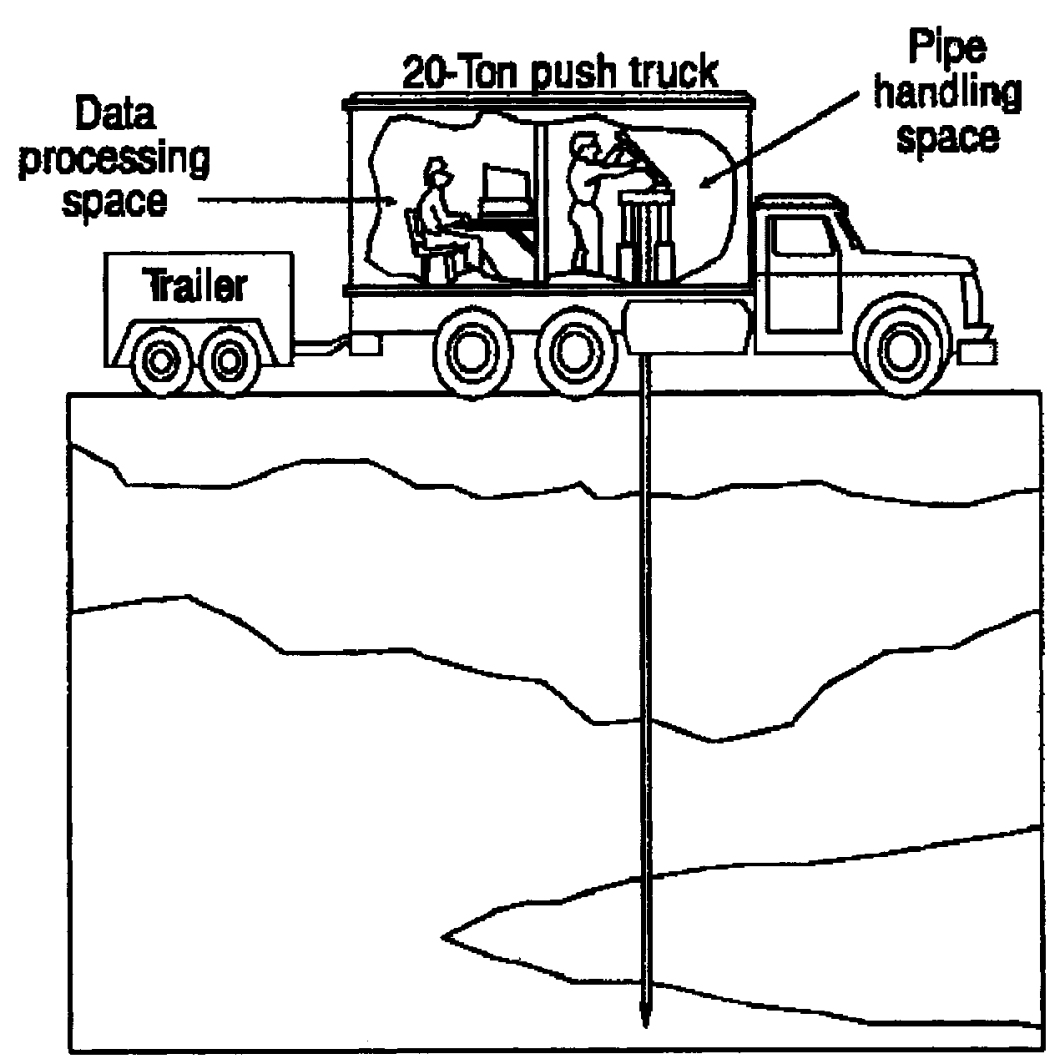

FIG. 1. Schematic of SCAPS truck during operation.

of site contamination because a small number of samples are taken. Widely spaced holes, in addition to few samples per hole, can miss important pockets of contamination. Clearly a technology is needed that possesses the following features: (1) cost effective, (2) rapid, (3) sufficient spatial resolution, and (4) adequate field screening sensitivity. The LIBS sensor probe deployed via the U.S. Army Corps of Engineers Site Characterization and Analysis Penetrometer System (SCAPS) meets the above requirements. This article describes the design and early field investigation results of a LIBS sensor in tandem with the SCAPS system to provide site screening for heavy metals.

\section{Plasma Development}

Soon after the laser was developed researchers noted that a focused, pulsed laser could produce dielectric breakdown of air and subsequent plasma generation. ${ }^{1}$ Early studies dealt with the plasma formation and dynamic nature of the plasma in air. Subsequently, researchers spectrally resolved the la-

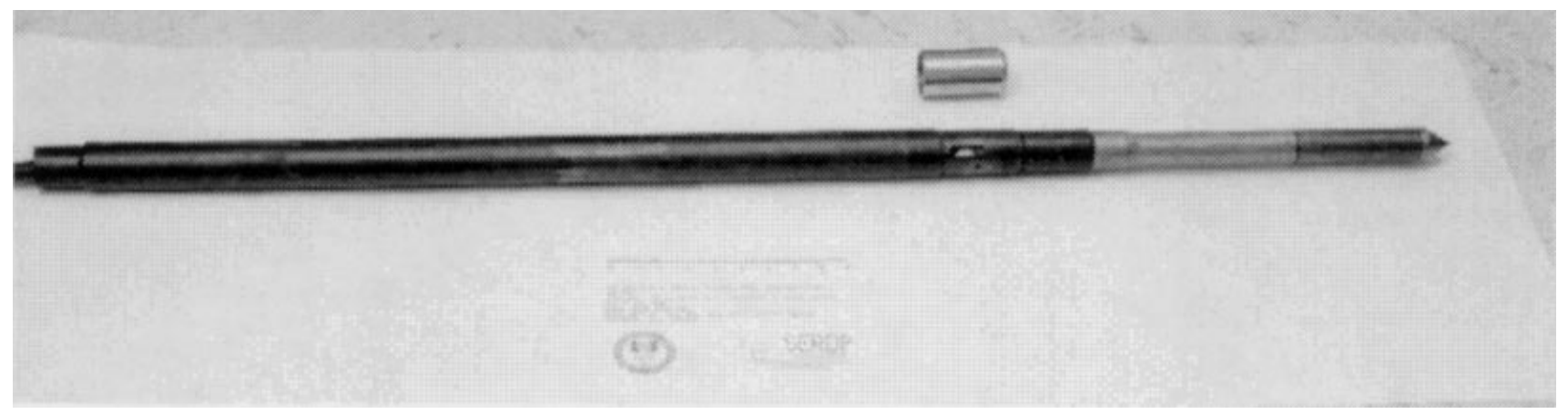

FIG. 2. LIBS sensor probe. Laser is located in the large-diameter (2 in.) section to the left. Total probe length is 70 in. Optical transmitter and receiver sections and slot are located in the probe region next to the sacrificial sleeve. Soil cone and sleeve classification sensors are the conical tip at the rightmost end and the cylindrical 6-in.-long region just to the left of the tip, respectively. A portion of the power/signal cable can be seen at far left. 
ser-produced plasma's emission to indicate the atomic species present. This technique was later termed laser-induced breakdown spectroscopy (LIBS). ${ }^{2-6}$ In the LIBS technique a laser provides a high-peak-power optical pulse focused to a high irradiance, causing rapid heating of the sample and ultimately resulting in generation of an ionized high-temperature $\left(\sim 5000 \mathrm{~K}\right.$ average temperature for soils $\left.{ }^{7}\right)$ plasma. Immediately after plasma formation, the emission spectrum consists primarily of broadband blackbody radiation from the hot plasma. As the plasma cools, the blackbody component decays and the line spectra from downward atomic transitions dominate. The line spectra of the emitted light indicate which atomic species are present within the plasma. With all other factors constant, the abundance of photons at the transition energy of interest is proportional to the species concentration. Spectroscopic analysis of the emitted light thus indicates the metal present and allows the metal's concentration to be determined.

\section{Previous Relevant LIBS Research}

LIBS has been applied by numerous researchers to a wide variety of sample types including air, single water droplets, ${ }^{8-11}$ liquid aerosols ${ }^{12-15}$ and solid aerosols. ${ }^{16-18}$ Some early research investigated the detection of gaseous elements. ${ }^{19}$ Others used LIBS to determine lithium, sodium, potassium, rubidium, cesium, beryllium, magnesium, calcium, boron, aluminum, ${ }^{20}$ and, later uranium. ${ }^{21}$ The earliest work done at WES concentrated on understanding breakdown in the simplest metal matrices: aqueous solutions and metals. ${ }^{22}$ Metals including copper, zinc, aluminum, tin, molybdenum, titanium, and iron were studied in solid form. ${ }^{23}$ Others studied mineralogical content of rocks with the use of LIBS. ${ }^{24}$ Most recently, soils have been studied. ${ }^{25-30}$ This work extends previous soil research by the authors and others through the development and demonstration of a LIBS sensor designed to analyze subsurface soils in situ.

\section{Experiment}

\section{System Design}

Description of SCAPS Operation with the LIBS Sensor. The SCAPS consists of an all-wheel-drive truck with a centrally mounted hydraulic ram capable of 20 tons of push force (see Figure 1). The truck's payload consists of a front room containing the hydraulic ram, push pipes, and penetrometer operator and a rear room containing all electronics and sensor system operator.

During operation the ram first forces the LIBS sensor pipe section (Figure 2) through a clearance hole in the bottom of the truck and into the ground. A hollow push pipe, which is $1 \mathrm{~m}$ long and has a $4.45-\mathrm{cm}$ outer diameter, is slid over the sensor pipe's trailing power/signal cable and screwed onto the top of the sensor pipe. As the sensor pipe continues downward, additional hollow push pipes are added every meter until the desired depth is reached. The soil geophysical sensor provides soil classification as the pipe is pushed. After the desired depth is reached, the probe begins retraction, leaving a sacrificial sleeve in the bottom of the hole. The laser starts firing through the now-exposed window (Figure 3 ) in the side of the probe. A fiber positioned a short distance from the plasma collects a portion of the plasma light for up-hole spectroscopic analysis. The system currently samples the soil every 0.87 in. of upward travel. After retraction is complete grout is poured into the hole by the SCAPS crew.

LIBS Instrumentation. In this section the LIBS probe design, software development and final system design are presented and discussed with emphasis on analysis of optical design trade-offs.

First, a discussion of the operation sequence and components utilized (Figure 4) is in order. Currently, the laser (a 1.25-in. diameter, 15 in. long, $80 \mathrm{~mJ} \mathrm{Nd:YAG} \mathrm{laser)} \mathrm{pro-}$ vides the master timing control for the system. When the laser is fired a portion of the energy bleeds through the dielectric-coated turning mirror and the Nd:YAG laser line filter and illuminates a $p-i$ - $n$ photodiode. The majority of the energy is focused on the soil wall creating a plasma. A portion of the plasma light is conveyed up hole to a CzernyTurner spectrometer equipped with a microchannel plate intensified charge-coupled device (ICCD) array. The electrical pulse from the $p-i-n$ photodiode travels up hole to a trigger circuit that defines the ICCD integration time and integration delay. The trigger circuit then instructs the PC to read out the ICCD. The data are acquired via a program developed at WES and described below. This program provides peak detection capabilities, indicating which atomic element is present, as well as an indication of confidence in peak labeling.

Software Design. Each time the spectrometer is powered up, a mercury lamp is used to define the 435.83-nm line and verify spectral accuracy in an absolute sense. This is the most basic level of spectral calibration. It was noted that once the center point of a spectral window is located correctly, a linear extrapolation to define the spectral locations of the outermost pixels is insufficient. Specifically, calculation of the central wavelength of pixels on the edge of any spectrum is not sufficiently correct if pixel central wavelength is considered only in a linear fashion. This nonlinearity necessitates the use of higher-order fitting coefficients in addition to the first order. In this procedure a fifth-degree polynomial is defined by utilizing at least six known transitions, preferably equally spaced over the full spectral window selected. Hollow cathode lamps are used to provide a variety of known spectral transitions for this work.

A secondary computer program was written to provide in situ calibration with the use of a third-order polynomial. Specifically, the spectral dimension of the LIBS data can at any time be recalibrated by entering wavelengths from known transitions present in the data. This routine is designed to be used primarily in postprocessing to recover lost calibration parameters caused by hardware failure or power outage.

Software was developed to perform all data-acquisition 


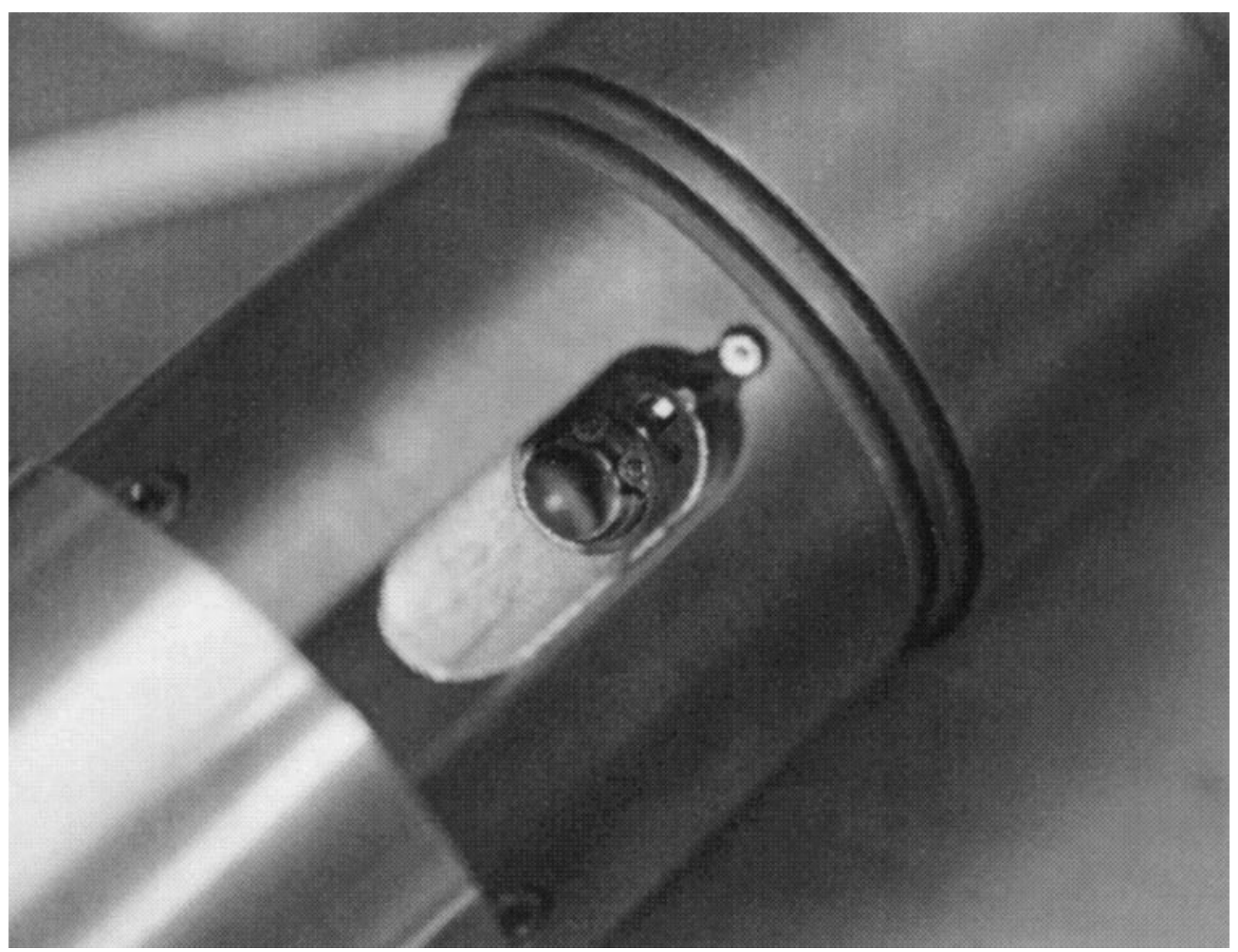

FIG. 3. Close-up photo of slot geometry. Laser output window is below snap ring. Optical receive fiber (small bright spot just above the right of the window) is illuminated from up hole for demonstration purposes. (The larger bright item above and to the right of the window and flush with the probe surface is a locking screw.) The sacrificial sleeve is slid down a bit and shown at bottom left. Probe tip is out of the picture at bottom left. For scale, the window is $1 \mathrm{~cm}$ in diameter and the illuminated fiber image is approximately $1 \mathrm{~mm}$ in diameter.

tasks and real-time analysis. After initial spectrometer calibration, a typical push sequence involves acquisition of soil stratigraphy data during the downward push and acquisition of LIBS data during the retract phase. After recording soil stratigraphy on the way down and reaching the desired depth, the spectrometer is scanned to the spectral region of interest for the desired metal. A test firing of the laser is performed within the sacrificial sleeve. Typically iron peaks are noted within the verification spectrum.

Table 1 lists the spectral emission lines defining the spectral center location for each metal of interest. These lines are the primary choices for each element based on line strength and lack of natural interferences. With the use of the 3600 -groove/mm grating in the 250 -mm focal length spectrometer the spectral width is $12 \mathrm{~nm}$.

After the test firing is complete, the probe begins retraction and laser firing starts. At this point the spatial separation of the data point is defined by the rate of retraction of the probe, which is adjustable, and the laser repetition rate, which is set at $0.3 \mathrm{~Hz}$. A common spatial separation is $0.8 \mathrm{~cm}$ per LIBS sample point. The laser provides the master timing signal for all software acquisition functions. Within $1 \mathrm{~s}$, the emission spectrum is displayed on the computer screen and the data are stored to disk. Figure 5, is a screen capture illustrating the data display. The horizontal axis indicates the wavelength in nanometers, and the vertical axis indicates the number of digital counts indicative of the irradiance at that wavelength.

An added feature of the software is postprocessing to find

TABLE 1. Preferred metal emission monitoring lines.

\begin{tabular}{ll}
$\mathrm{Cd}$ & $508.582 \mathrm{~nm}$ \\
$\mathrm{Cr}$ & $425.435 \mathrm{~nm}$ \\
$\mathrm{Hg}$ & $435.833 \mathrm{~nm}$ \\
$\mathrm{~Pb}$ & $405.781 \mathrm{~nm}$ \\
$\mathrm{Zn}$ & $481.053 \mathrm{~nm}$ \\
\hline
\end{tabular}




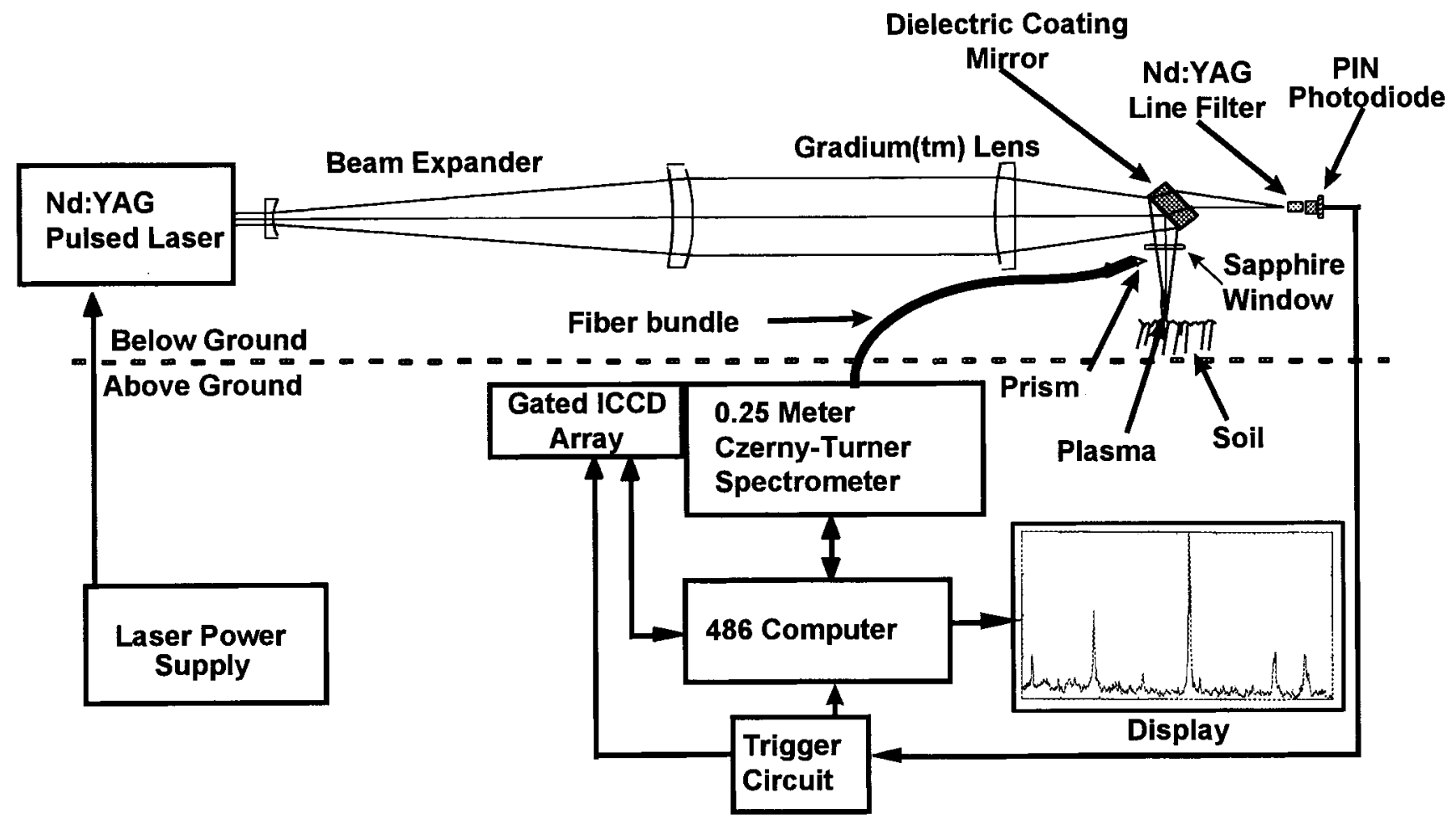

FIG. 4. Block diagram of WES LIBS/SCAPS system. Items above the solid line are inside the probe; all other items are located in the truck.

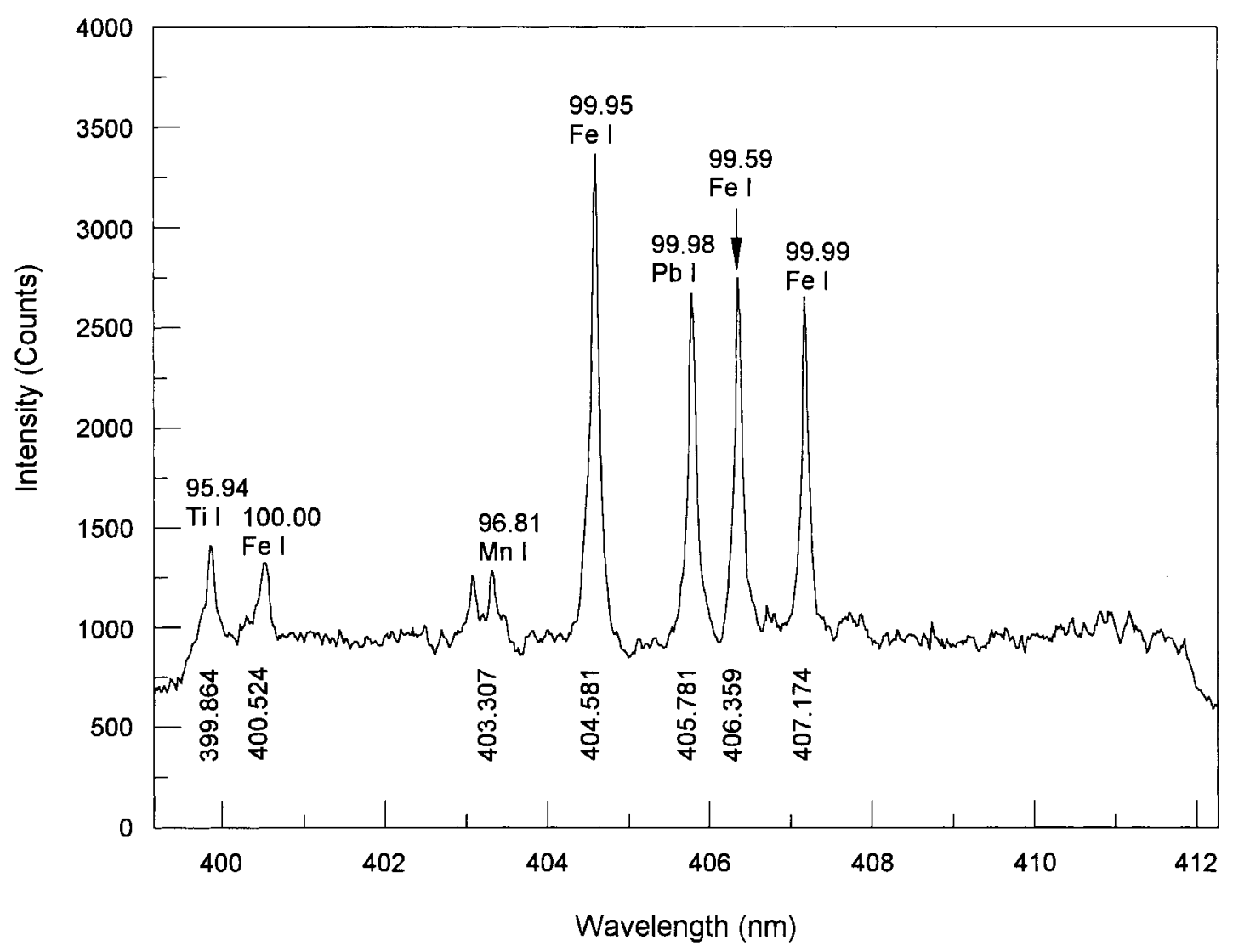

FIG. 5. Representative single spectra, lead peak. Note that corresponding wavelengths of identified peaks are listed on the $X$ axis. 
peaks and determine the peak-finding confidence. NIST digital database number 38 ("NIST Spectroscopic Properties of Atoms and Atomic Ions Database") was utilized in determining peak spectral locations. Transitions and excitation states from 200 to $1100 \mathrm{~nm}$ for 50 of the most common elements found in soils plus contaminant metals were taken from the NIST database and used for peak analysis. A simple but effective figure of merit was devised to aid in peak selection. The peak-ranking coefficient $R$ is defined as the ratio of the natural element abundance in soils, $C_{\text {natural }}$, and the difference between the measured and theoretical peak positions:

$$
R=\frac{C_{\text {natural }}}{\left|\lambda_{\text {measured }}-\lambda_{\text {theoretical }}\right|}
$$

The highest and second highest ranked transitions, $R_{1}$ and $R_{2}$, are compared to indicate a confidence in peak identification:

$$
\text { Confidence }=\frac{\left|R_{1}-R_{2}\right|}{R_{1}} \cdot 100
$$

If the highest rank is much greater than the second, then the peak label corresponding to the highest rank is considered more likely. Thus with a maximum of 100, each peak's label is given a confidence indicator. This provides an indicator to use in addition to experience when identifying peaks present in the spectra. Based on use of this feature peaks with a confidence of less than 70 are not displayed. Figure 5 illustrates the confidence indicator in use; note the three central iron peaks surrounding the lead peak. In this case the lines are known from experience, and the $>99$ confidence value corroborates our experience and indicates a very high degree of confidence in peak selection.

Optical Transmitter Design. Previous LIBS lab work demonstrated that if the output window and sample are in contact, damage to the window will occur from the hightemperature plasma. This damage may include minor pitting, localized melting, and, in extreme cases, complete fracture of the glass. A fractured or pitted window will provide signal attenuation that exhibits a complex dependence on the degree of pitting of the window. If the same portion of the window is used for transmitting and receiving, then clearly the laser and the plasma will both be attenuated. Furthermore, the quartic spectral dependence on scattering with respect to light frequency ${ }^{31}$ indicates how the relative line strengths will be affected. Specifically, as the window condition worsens the shorter wavelengths will scatter much more (fourth power!) than the longer wavelengths.

The fracturing problem is avoided by providing a separation between the soil and output window, allowing for very low irradiance values at window surfaces $\left(\sim 0.01 \mathrm{GW} / \mathrm{cm}^{2}\right)$, eliminating the chance of damage. Comparison of various operational scenarios led to selection of a recessed window (Figure 3), which would allow operation during probe retraction. A slot with a gradual slope was chosen on the as- sumption that it may minimize clogging. A $1: 2$ scale model of this geometry was tested, and afterward a full-scale probe was designed with this recessed window and slot geometry. The probe diameter serves to prepare the soil and define the separation between the soil wall and window. Note that different soil types, such as expansive clays, may expand to reduce the window soil offset. This expansion should be fairly small and inconsequential if the delivery system has a large depth of focus. The large depth of focus and high pulse peak irradiance ensure that minimum-breakdown thresholds will be met even with slight offsets in the soil-window standoff distance. The stand-off geometry has potential weaknesses. If the stand-off area is clogged during retraction, no further data can be acquired during that retraction. Clogging has not been a significant problem to date, as over 50 holes have been pushed thus far with only one instance of clogging. Clogging is easy to diagnose, because, if the laser power is increased and no spark data are noted, one can be sure that the transmit and/or receive portions are obscured.

The goal of the transmit section is to maximize irradiance on the target surface to increase plasma temperature, resulting in brighter emission lines. To that end, a custom optical transmit section was designed. The first half of the optical system consists of an inverted Gallilean telescope to expand the beam. Given the same focal length, the larger beam is advantageous, as it can be focused to a smaller spot size compared to a smaller-diameter beam resulting in hotter plasmas. ${ }^{32}$ The larger beam, in tandem with the recessed window, results in lower irradiances through the window, as previously indicated. Furthermore, the WES-designed F/3.2 transmit optics have a larger depth of field than smaller F/\# optics, but still maintain a focused-beam spot diameter on the order of 30 microns. The transmit section utilizes the power of axial gradient index glass materials, specifically Gradium $^{\mathrm{TM}}$ by Lightpath Inc., to achieve a diffraction-limited focused laser spot with only three optical elements. The entire transmit portion of the system, including the Gra$\operatorname{dium}^{\mathrm{TM}}$ lens, were optimized with the use of the Zemax ${ }^{\mathrm{TM}}$ optical design program.

Optical Receiver Design. There are two basic optical receiver design types: imaging and nonimaging. In an imaging scenario the spark is imaged on the surface of the receiving fiber with the use of focusing optics including lenses and/or mirrors. In a nonimaging scenario there are no intervening focusing optics between the spark and fiber.

The imaging technique results in more efficient light collection, but systems using this approach must be designed very carefully. Care must be taken to ensure that the light collected by the optical receiver is in fact representative of the plasma as a whole. Most importantly, receiver systems should avoid introducing an excitation-state elemental bias into the data.

An excitation-state elemental bias occurs when one spark event results in a different spectrum received even though the plasma spectrum is constant from spark to spark. This type of bias can be introduced in a number of ways. As Adrain and Watson ${ }^{4}$ note, atomic transitions of different ex- 
citation states and ionization energy radiate from different radial regions in the plasma. Specifically, due to the radially decreasing plasma temperature distribution, atoms in the more highly ionized states are found in the hot plasma core, and neutral atoms are located in the plasma periphery. Thus, the downward optical transitions from singly and doubly ionized atoms will only occur in the core, and downward optical transitions characteristic of neutral atoms will radiate from the plasma's periphery. Thus, if the image of the spark moves outside the receiver's field of view, a portion of the spark image corresponding to the neutral transitions will not be collected, resulting in an excitation-state elemental bias. Thus if the image of the plasma is bigger than the field of view, the optical system will preferentially reduce the signal from the nonionized atoms.

Nonimaging collection is typically much less efficient, scaling as the ratio of imaging lens area to fiber area if the same object-to-image distance is used in both cases. This is the largest single drawback of nonimaging collection. If a fiber is placed $10 \mathrm{~mm}$ away from the plasma and the fiber's numerical aperture is 0.39 , the collection area has a diameter of $4.5 \mathrm{~mm}$. The spark diameter is on the order of $0.5 \mathrm{~mm}$ in diameter; thus formation of the spark outside the collection area or field of view is not an issue. Thus species bias is of no concern in the nonimaging scenario listed here, and all species radiating from the plasma will be collected equally. This is clearly important for quantitative LIBS comparison of line strengths, which is necessary in concentration determination.

Based on the preceding information, it was decided to utilize a nonimaging receiver design with the fiber starting at the expected plasma location.

Once a nonimaging approach was chosen the fiber selection could begin. The receiver optics consisted of a 2-mm, right-angle, BK7 microprism used to help the inflexible, 1-mm core diameter, TECS ${ }^{\mathrm{TM}}$-clad, 71-cm-long, fiber view the plasma. To minimize contamination of the prism, it is located in a slot within the recessed portion of the probe (Figure 3). To date, contamination of this prism during operation has been minimal, requiring only mild cleaning at the end of each retraction. Evidently, this geometry allows for a robust optical system, as no elements have been damaged during any pushes. The $71-\mathrm{cm}$ section then couples within the probe to a 19-fiber 200-micron-diameter core silica/silica circular bundle. The use of the short rigid fiber allows the probe to be disconnected from the power/signal cable and allows uniform illumination of the 19 fibers. The 19-fiber bundle conveys the light up hole to a short 19-fiber, circular-to-linear bundle that introduces the light into a Chromex model 250 is imaging spectrometer equipped with an Oriel Instaspec 5 microchannel plate ICCD.

\section{Results and Discussion}

\section{Field Investigation Results}

The probe was fabricated by the WES machine shop, assembled by the authors, and tested in the fall of 1996. The first system check was performed at WES in early August 1996. Prior to installation in the SCAPS truck, basic laboratory system operation tests were performed to ensure system operability.

WES Field Investigation. The probe was installed in the SCAPS truck and preliminary tests commenced at WES. Due to the naturally occurring chromium in the local soil the 425.435-nm chromium line and surrounding region were monitored during initial check. Figure 6 illustrates representative spectra obtained during the initial WES testing. This spectrum represents the average of 10 shots acquired while the probe was motionless at a depth of $11 \mathrm{ft}$.

Soil samples were taken to validate the presence of chromium. Five samples were pulled and 18-in.-long sections were homogenized. Metals analysis was performed with an ICP spectrometer. Naturally occurring chromium concentrations ranged from 14.5 to $25.5 \mathrm{ppm}$ for these samples. ${ }^{33}$

Louisiana Army Ammunition Plant (LAAP) Field Investigation. The preliminary LIBS probe tests at WES successfully demonstrated system functionality. The second stage of this field investigation was performed at the Louisiana Army Ammunition Plant (LAAP) in Minden, LA. Several processes in ammunition manufacture result in heavy metal by-products, many of which can be found at this formerly used ammunition plant. The LAAP environmental safety officer suggested several known and potentially metal-contaminated sites. The 3-day length of the field investigation limited the study to four areas and a total of nine pushes. Representative data of chromium are shown in Figure 7.

The first site investigated is called landfill, a waste pond that was used to dump primarily chromium-bearing sludge. This site was well marked behind a locked gate and had several monitoring wells. The contamination was localized in the approximately $30-\mathrm{m}$ by $30-\mathrm{m}$ sludge pond. Four pushes were made at this site with the spectrometer centered at the $425-\mathrm{nm}$ chromium peak in all cases. Chromium was readily detected in all holes pushed at landfill.

The first push at the landfill site went below the water table to a depth of $15 \mathrm{ft}$. Interestingly, although the data from the bottom of the hole below the water table were unusable, after the water drained away from the window, reasonable quality spectra were obtained at shallower depths (4 $\mathrm{ft}$ up to the surface). This ability to recover after being pushed below the water table obviously yields a more robust instrument.

Chromium was found in three of four areas tested; lab results indicated concentrations ranging from 12.8 to $19.7 \mathrm{ppm}$.

Keesler Air Force Base Field Investigation. Sixteen penetrometer pushes were made at a small-arms firing range at Keesler Air Force Base, Biloxi, MS during a 3-day test at the end of September 1996. The area tested was at the base of an earthen bullet impact berm (Figure 8) that stopped bullets from two parallel firing ranges. The area investigated overlapped both firing ranges, including an intermediate dead zone. In reference to the figure, when facing the impact berms the left berm is barren and is in the upper right of the 


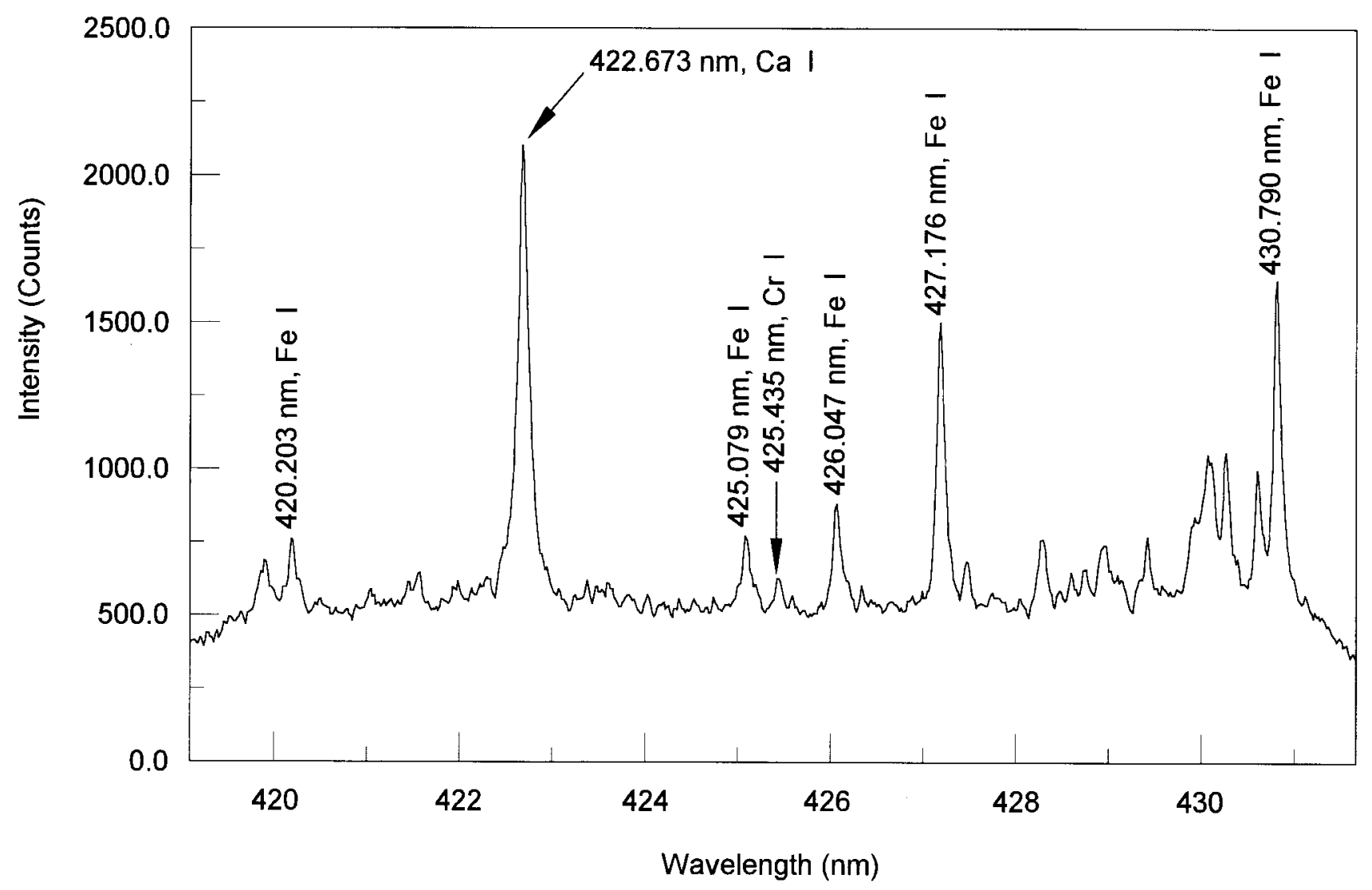

FIG. 6. LIBS/SCAPS probe Cr data collected at WES; average of 10 spectra at a depth of $11 \mathrm{ft}$.

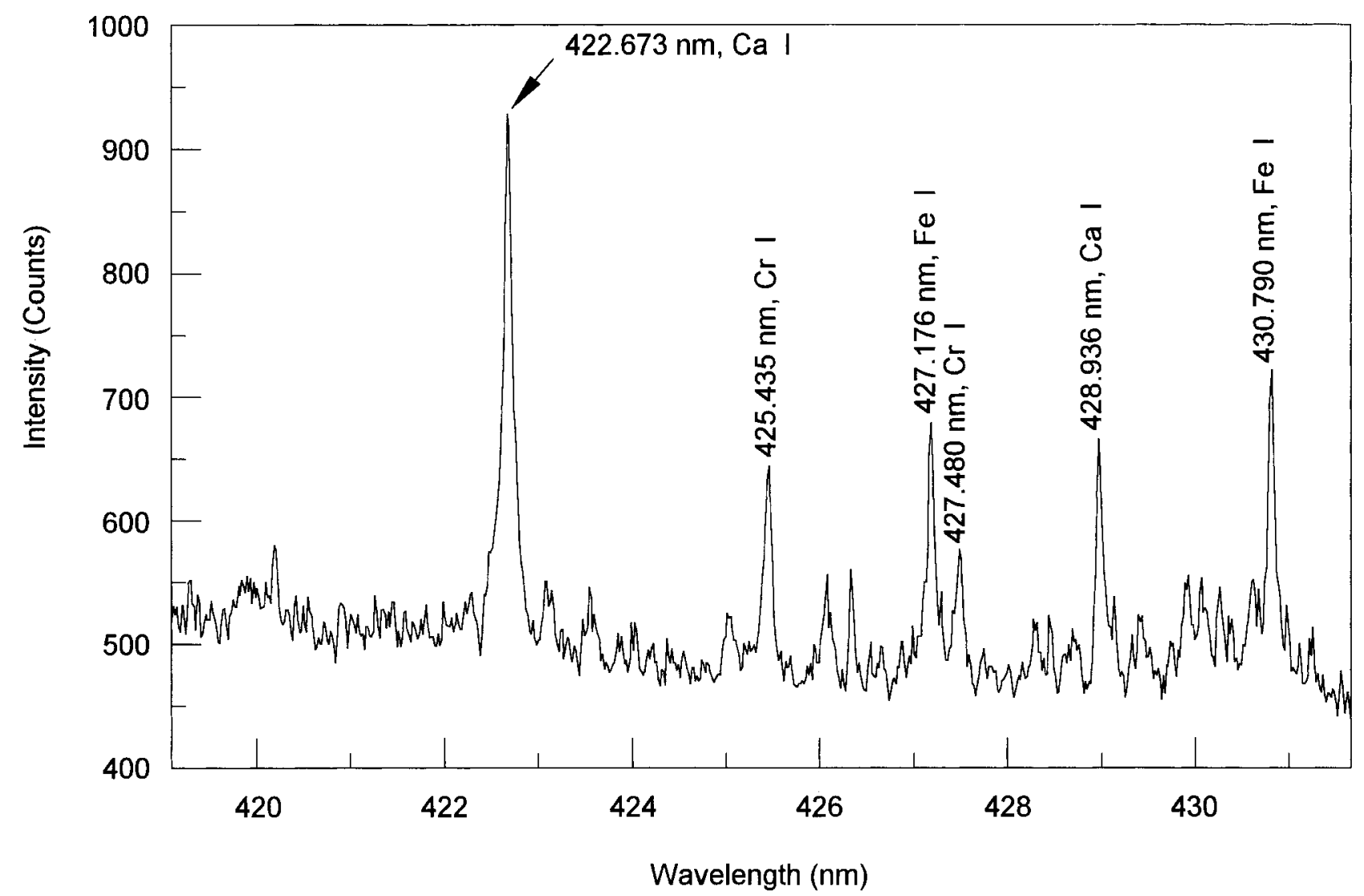

FIG. 7. WES LIBS/SCAPS probe Cr data collected at LAAP, average of 10 spectra at 2-ft depth. 


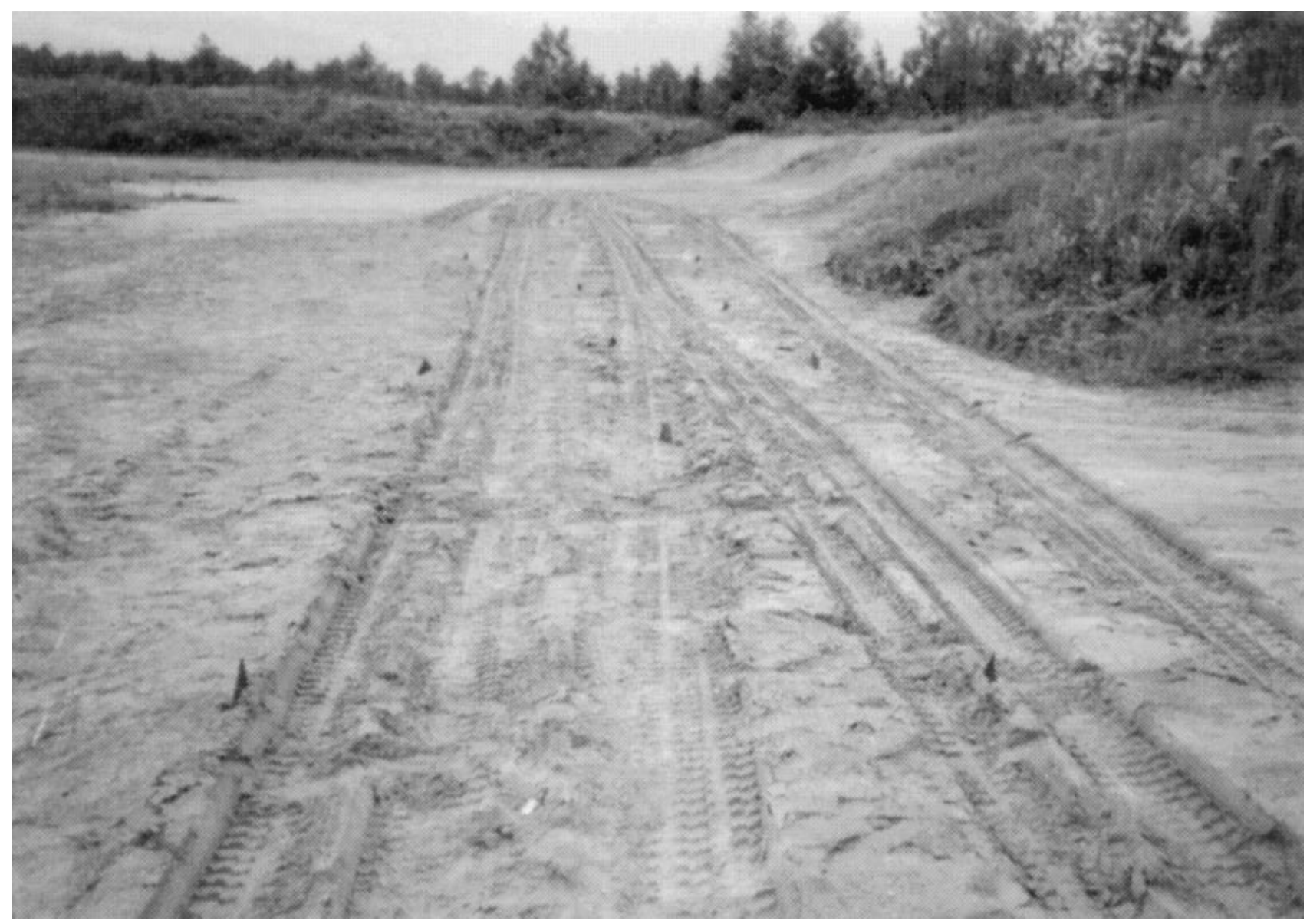

FIG. 8. Keesler AFB small arms firing range lead test area. Flag locations indicate push locations. Clearing at upper center is one impact area. At far right of photo, the left edge of the adjacent impact area is seen.

figure. The tall grassy area seen on the top right of Figure 8 is the dead zone, and the right impact berm is just outside the figure at the center and bottom right of the figure. Three parallel rows of flags can be seen, indicating the location of the pushes. If little leaching of lead occurred, one would expect the contamination to be primarily near the surface. Furthermore, intuition would indicate (and results should show) a dead zone with little or no lead contamination between the two firing ranges. Figure 9 displays an interpolated color-coded subsurface volume plot that indicates the strength of the lead 405.78-nm peak, normalized by the sum of all diode elements. It is clear, as was theorized, that the bulk of the concentration is in two regions, separated by the dead zone mentioned. The data acquired indicate the contamination is shallow, typically $3 \mathrm{ft}$ deep and shallower. The depth dimension is exaggerated for clarity and covers just $5 \mathrm{ft}$; the longest dimension is parallel to the three rows of flags and covers $82 \mathrm{ft}$ (top to bottom in Figure 8) and the across-row distance is $12 \mathrm{ft}$ (left to right in Figure 8). Future efforts will concentrate on converting this line strength to a more quantifiable contamination estimate. Specialized software developed at WES for SCAPS visualization was used to interpolate a volume shown in Figure 9.

Joliet Army Ammunition Plant (JAAP) Field Investigation. A field investigation of JAAP in Joliet, IL was performed in August 1997. Lead azide, used in fuse manufacture, contaminates a portion of the site. A plot of the normalized 405.78-nm lead peak as a function of depth from a single hole (Figure 10) indicates a high degree of contamination near the 2 -ft depth location. The peak intensity was normalized by the sum of the intensities of all diode elements in the spectrum. This aids in reducing the effect of pulse-topulse laser energy variations on spectral intensity. A sample taken from a hole about $30 \mathrm{ft}$ north of the hole just mentioned and 18 in. below the surface yielded the highest contamination level of 31,000 ppm lead. ${ }^{34}$ In previous field investigations of other sites every plasma spectrum contained the background peaks of the soil. In one interesting case, the iron peaks that are typically present in the lead spectral region were not present, indicating that a pocket of material had been encountered that had no soil mixed in. The implications of this are significant, as other researchers ${ }^{35}$ often assume certain materials are present in uniform amounts. Although it is true that certain elements, like iron, may be present, the assertion that they are present in uniform concentration is suspect. More importantly, there are situations in field screening where pockets of pure contaminant exist, and in these cases spectra without the typical background peaks will be present. Furthermore, it is reasonable to expect that these same sampled locations will represent the highest 


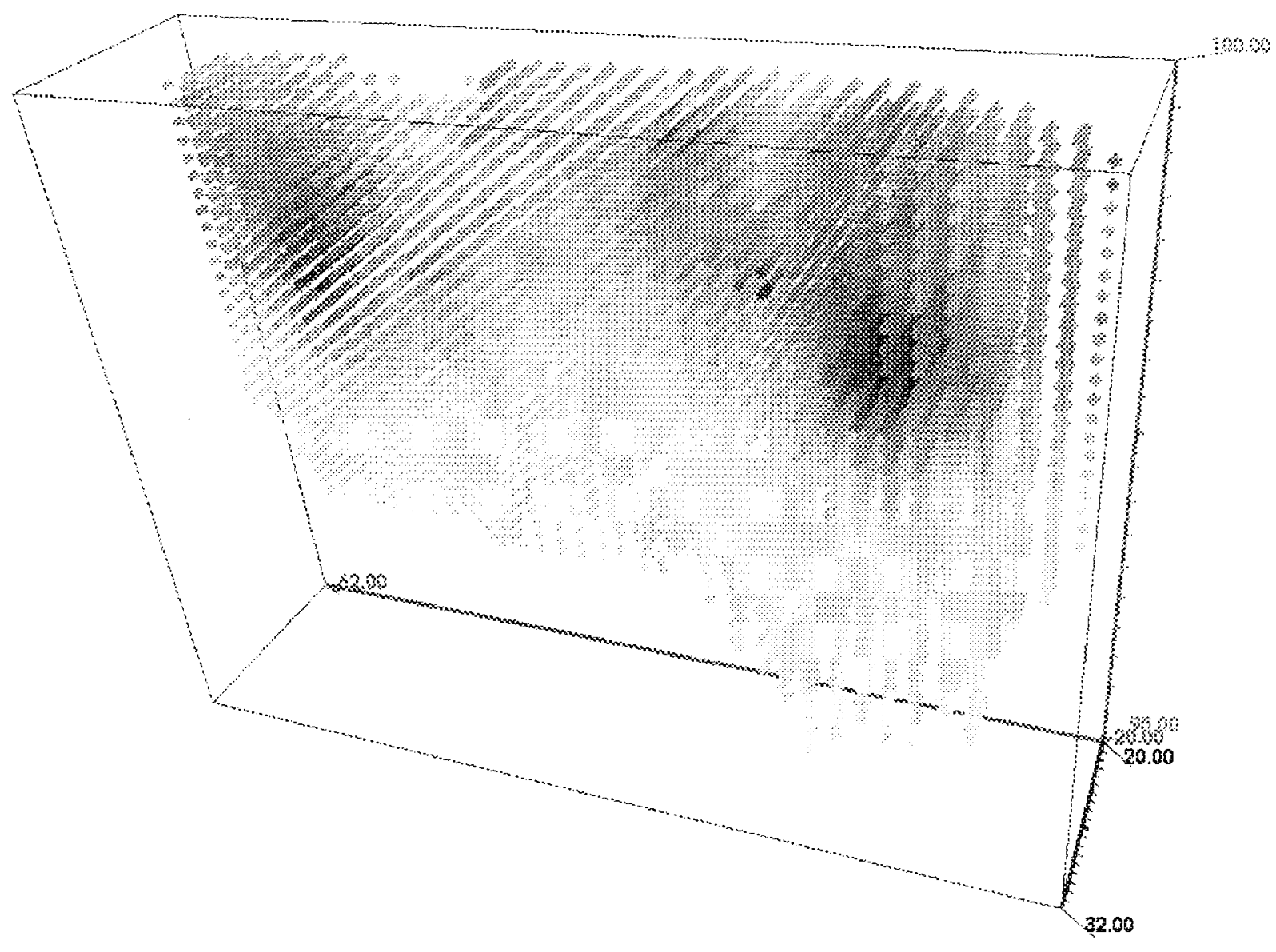

Scalar Value $\operatorname{Min} 1.29$

FIG. 9. Interpolated volume rendering of 405.78-nm lead peak strength at Keesler AFB. Note that the depth dimension is greatly exaggerated for clarity. Darker shading indicates a stronger lead peak signal.

concentrations. Figure 11 displays two individual spectra from which two points of Figure 10 (just to the left and right of the largest peak in Figure 10) were derived. A 2,000 count offset has been added to the upper spectrum to aid in visualization. The central peak in both spectra is the lead 405.78-nm peak. The upper spectrum clearly displays the common iron peaks (one to the left and the two to the immediate right of the lead peak) and a strontium peak (to the far right). Clearly, normalization on nonexistent peaks is not feasible. In addition, performing plasma diagnostics such as the two-line ratioing method for plasma temperature determination would be impossible on this spectrum.

Discussion. The LIBS/SCAPS probe continues to perform well, acquiring valuable spectral subsurface data, in a variety of conditions. The work must now concentrate on quantifying the response of the probe in order to obtain semiquantitative concentration predictions. It has been noted from previous lab work at WES that soil grain size and soil moisture affect the LIBS response significantly. For the same contaminant concentration and moisture content, sands will provide a larger signal than clay soils; likewise, dry soils will provide a larger signal than wet soils. Although these trends are known, measurement of these parameters should be performed in order to account for the effects. Surely, without knowledge of these parameters a sensor could predict concentrations, but the confidence interval describing the concentration would be comparatively large. With a more informed estimate of the site conditions, via knowledge of the moisture and grain size, concentration estimates will have significantly smaller confidence intervals; that is, more accurate results would result.

It is envisioned that typical operation of the probe leading to the aforementioned informed estimate will include verification sampling implemented as follows. The system will perform a series of pushes to obtain a rough feel for the site conditions. Then, in an area that has significant apparent 


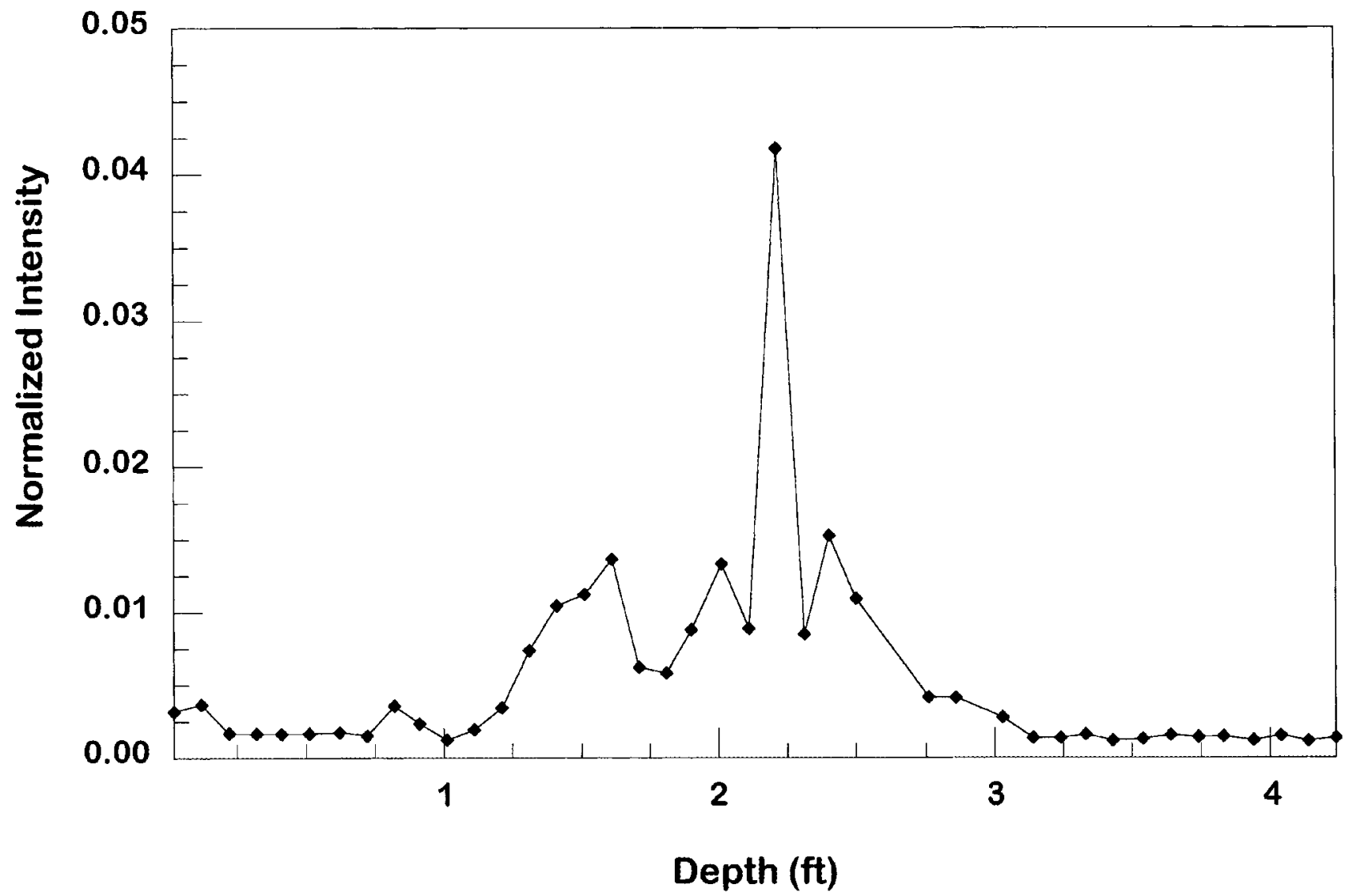

FIG. 10. Normalized 405.78-nm lead peak as a function of depth, Joliet Army Ammunition Plant.

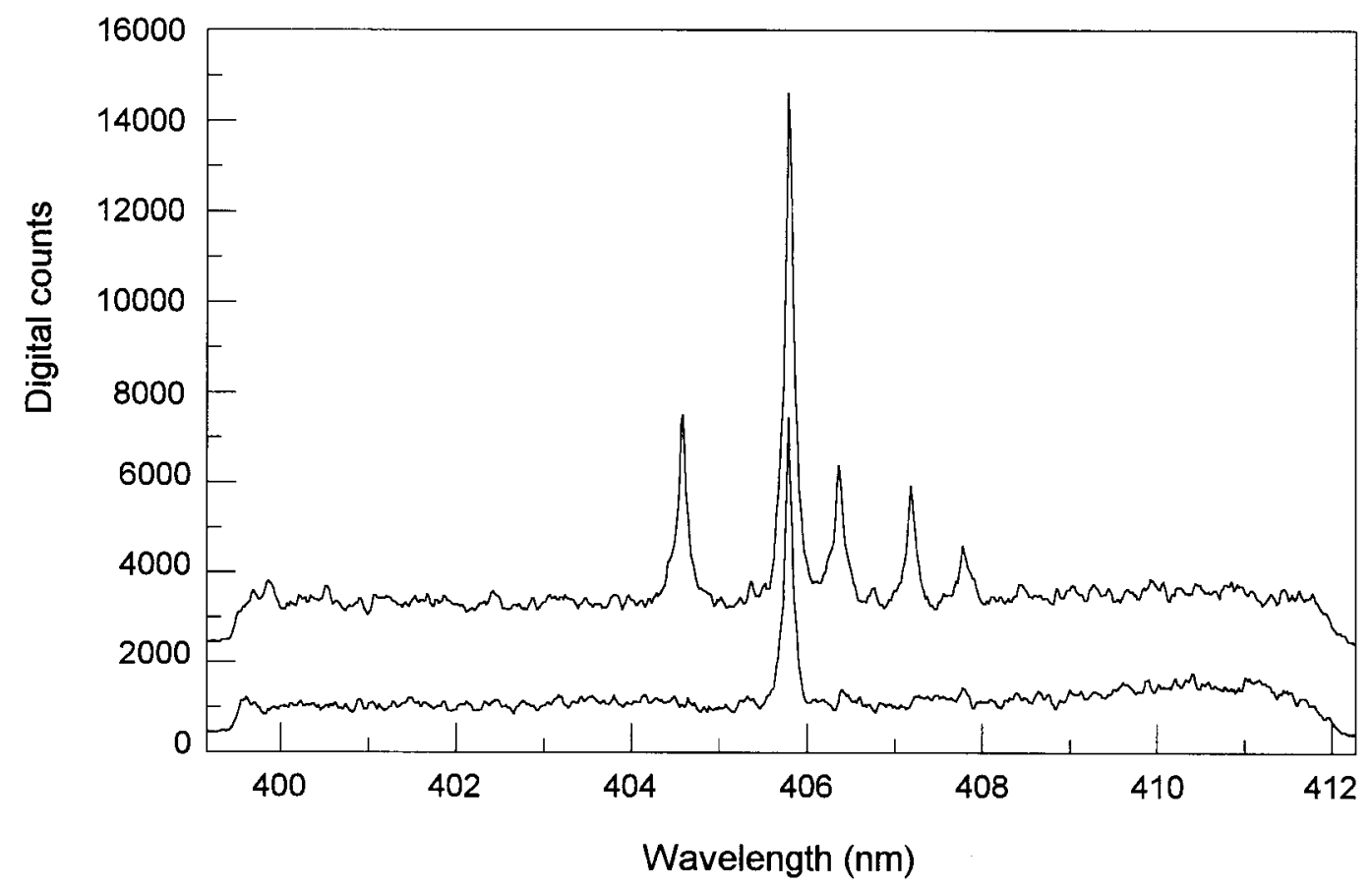

FIG. 11. Superimposed spectra from JAAP centered on the 405.78-nm lead transition. The upper spectrum contains iron peaks that are commonly visible in the 405-nm region. The lower spectrum does not contain these peaks and would be impossible to analyze with line ratioing techniques. 
contamination, a sample hole will be pushed, taking a continuous core sample over a depth equal to or greater than the contamination depth noted for the orientation holes. This sample core will form the basis for verification and a benchmark for multivariate comparison. Several pushes (3 or 4) will be made surrounding the core. If the data from the pushes are highly similar, then it is surmised that the central sampled core should have a contaminant and soil profile similar to the surrounding pushes. The core should be then sampled at a spatial rate great enough to ensure that the spatial structure of the soil type, moisture, and contamination are accurately recorded. As has been mentioned, two major factors affect LIBS: (a) soil moisture ${ }^{15,22,25,26}$ and (b) soil grain size. ${ }^{26,30}$ Other researchers indicate that metal speciation also affects the LIBS signal. ${ }^{30}$ Significant variations in soil moisture and grain size can be expected within a push and between pushes. Metal speciation, however, will in many cases be known, and for most DoD sites will be the same within a given local region Thus, real-time in situ speciation is not viewed as a requirement for most DoD sites; rather, speciation via site history and/or lab verification should be sufficient. It is thought that the range of soil types and grain sizes present within a small test area will be largely present in the continuous core sample. Likewise, from one push to another, the vertical moisture profiles are expected to correlate highly. Thus, the range of expected soil moisture levels within the test area should be very close to the moisture levels in the continuous core. In this way, if a multivariate space consisting of (a) LIBS-normalized peak signal strength, (b) soil moisture, (c) soil grain size; and (d) contaminant type is defined and verification data are acquired from the continuous core, most of the data acquired in other test holes at the site should lie within the multivariate space defined by the continuous core.

\section{Conclusions}

Researchers at WES have successfully designed, manufactured, and tested a LIBS/SCAPS sensor system for the detection of heavy metals that incorporates a compact, pulsed laser packaged in the probe. Previous lab work indicated that the output window should be located away from the soil in order to avoid plasma-caused damage to the window and related problems. A recessed slot geometry was chosen to satisfy this requirement. Although the slot geometry has worked well and clogging is rare, acquisition of LIBS data below the water table has not been demonstrated. Calibration, peak identification, and peak confidence software was developed and demonstrated. A noncolinear optical transmit/receive geometry was designed with the use of a computer-optimized lens group, including a custom gradient index lens. A nonimaging receiver approach was designed and demonstrated. The probe was tested successfully in the lab. Field investigations at WES, LAAP, Keesler AFB, and JAAP demonstrated the probe's capabilities in soils ranging from sandy to expansive clays and its ability to see two target metals: chromium and lead. A volume plot of lead line strength based on Keesler data agrees with the predictions that the contamination plot should be bimodal and located at shallow depths. Results from JAAP indicate that contaminants may be present with little or no mixing with host soil. In these cases performing procedures such as twoline plasma temperature determination and ratioing based on the existence of certain host soil spectral lines is impossible. Although the approach seems valid, it remains to be seen if empirical quantification with the use of a verification core as well as additional soil moisture and soil grain size data will result in more accurate concentration predictions.

\section{Acknowledgments}

The SCAPS project is a joint Army, Navy, and Air Force program to develop and demonstrate innovative site characterization technologies. Funding for the research, development, and field demonstration of the LIBS probe described in this article was furnished by the Strategic Environmental Research and Development Program (SERDP). Permission was granted by the Chief of Engineers to publish this information.

\section{References}

1. F. Brech and L. Cross, "Optical Microemission Stimulated by a Ruby Laser," Appl. Spectrosc. 16, 59, (1962).

2. J. M. Baldwin, "Comment on 'Laser Evaporation and Elemental Analysis"” J. Appl. Phys. 44, 3362-3364, (1974).

3. R. H. Scott and A. Strasheim, in Applied Atomic Spectroscopy, ed. by E. L. Grove, Plenum Press, New York, 1978, pp. 73-118.

4. R. S. Adrain and J. Watson, "Laser Microspectral Analysis: A Review of Principles and Applications" J. Phys D: Appl. Phys. 17, 1915-1940, (1984).

5. L. Moenke-Blankenburg, Laser Microanalysis, Wiley, New York, 1989, pp. 93-181.

6. L. J. Radziemski and D. A. Cremers, Laser-Induced Plasmas and Applications, Marcel Dekker Inc., New York, 1989, pp. 295-326.

7. A. S. Eppler, D. A. Cremers, D. D. Hickmott, M. J. Ferris and A. C. Koskelo, "Matrix Effects in the Detection of $\mathrm{Pb}$ and $\mathrm{Ba}$ in Soils Using Laser-Induced Breakdown Spectroscopy," Appl. Spectrosc. 50, 11751181, (1996).

8. R. K. Chang, J. H. Eickmans, W. Hsieh, C. F. Wood, J. Zhang and J. Zheng, "Laser-Induced Breakdown Spectroscopy in Large Transparent Water Droplets" Appl. Opt. 27, 2377-2385, (1988).

9. J. B. Zheng, W. F. Hsieh, S. C. Chen and R. K. Chang, "Temporally and Spatially Resolved Spectroscopy of Laser-Induced Plasma from a Droplet" Opt. Lett. 13, 559-561, (1988).

10. A. Biswas, H. Latifi, L. J. Radziemski, and R. L. Armstrong, "Irradiance and Laser Wavelength Dependence of Plasma Spectra from Single Levitated Aerosol Droplets" Appl. Opt. 27, 2386-2391, (1988).

11. H. A. Archontaki and S. R. Crouch, "Evaluation of an Isolated Droplet Sample Introduction System for Laser-Induced Breakdown Spectroscopy" Appl. Spectrosc. 42, 741-746, (1988).

12. L. J. Radziemski, T. R. Loree, D. A. Cremers and N. M. Hoffman "Time Resolved Laser-Induced Breakdown Spectrometry of Aerosols" Anal. Chem. 55, 1248-1252, (1983).

13. H. A. Archontaki and S. R. Crouch, "System for Laser-Induced Breakdown Spectroscopy" Appl. Spectrosc. 42, 5, (1988).

14. K. W. Holtzclaw, J. Moore and C. L. Senior, "Real-time optical measurement of alkali species in air for jet engine corrosion testing," 31st Aerospace Sciences Meeting \& Exhibit, Reno, Nevada, 1993. 
15. D. E. Poulain and D. R. Alexander, "Laser-Induced Breakdown Spectroscopy of Liquid Aerosols: Droplet Salt Concentration Measurements," Appl. Spectrosc. 49, 569-579, (1995).

16. L. J. Radziemski, T. R. Loree, D. A. Cremers and N. M. Hoffman, "Time-Resolved Laser-Induced Breakdown Spectrometry of Aerosols," Anal. Chem. 55, 1246-1252, (1983).

17. D. K. Ottesen, L. L. Baxter, L. J. Radziemski and J. F. Burrows, "Laser Spark Emission Spectroscopy for In Situ, Real-Time Monitoring of Pulverized Coal Particle Composition," Energy \& Fuels 5, 304-312, (1991).

18. W. L. Flower, "A Laser-Based Technique to Continuously Monitor Metal Aerosol Emissions," Fuel Processing Technology 39, 277-284, (1984).

19. D. A. Cremers and L. J. Radziemski, "Detection of Chlorine and Fluorine in Air by Laser-Induced Breakdown Spectrometry" Anal. Chem. 55, 1252-1256, (1983).

20. D. A. Cremers, L. J. Radziemski and T. R. Loree, "Spectrochemical Analysis of Liquids Using the Laser Spark," Appl. Spectrosc. 38, 731740, (1984).

21. J. R. Wachter and D. A. Cremers, "Determination of Uranium in Solution Using Laser-Induced Breakdown Spectroscopy" Appl. Spectrosc. 41, 1042-1048, (1987).

22. B. H. Miles, J. Cortes and E. R. Cespedes, "Laser-Induced Breakdown Spectroscopy Final Report", final report of ILIR project, FY91-92, WES Executive Office, 1992.

23. D. A. Cremers, "The Analysis of Metals at a Distance Using Laser-Induced Breakdown Spectroscopy" Appl. Spectrosc. 41, 572-579, (1987).

24. K. J. Grant, G. L. Paul and J. A. O'neill, “Quantitative Elemental Analysis of Iron Ore by Laser-Induced Breakdown Spectroscopy" Appl. Spectrosc. 45, 701-705, (1991).

25. J. Cortes, E. R. Cespedes and B. H. Miles, "Development of LaserInduced Breakdown Spectroscopy for Detection of Metal Contaminants in Soils," U.S. Army Engineer Waterways Experiment Station, Technical Report No. IRRP-96-4, 1996.
26. R. Wisbrun, I. Schechter, R. Niessner, H. Schröder and K. L. Kompa, "Detector for Trace Elemental Analysis of Solid Environmental Samples by Laser Plasma Spectroscopy," Anal. Chem. 66, 2964-2975, (1994).

27. D. R. Alexander and D. E. Poulain, "Quantitative Analysis of the Detection Limits for Heavy Metal Contaminated Soils by Laser-Induced Breakdown Spectroscopy," U.S. Army Corps of Engineers Waterways Experiment Station, Miscellaneous Paper No. IRRP-97-2, 1997.

28. D. A. Cremers, J. E. Barefield II and A. C. Koskelo, "Remote Elemental Analysis by Laser-Induced Breakdown Spectroscopy Using a FiberOptic Cable" Appl. Spectrosc. 49, 857-860, (1995).

29. D. R. Alexander, D. E. Poulain, M. S. Khlif and E. R. Cespedes, "Influences on Detectability of Heavy Metals in Soils by Laser-Induced Breakdown Spectroscopy," IGARSS'96, Lincoln, Nebraska, 27-31 May 1996

30. A. S. Eppler, D. A. Cremers, D. D. Hickmott, M. J. Ferris and A. C. Koskelo, "Matrix Effects in the Detection of $\mathrm{Pb}$ and $\mathrm{Ba}$ in Soils Using Laser-induced Breakdown Spectroscopy" Appl. Spectrosc. 50, 11751181, (1996).

31. E. Hecht and A. Zajac, Optics, Addison-Wesley, New York, 1979, p. 240.

32. A. E. Siegman, Lasers, University Science Books, Mill Valley, CA, 1986, p. 676.

33. U.S. EPA, "Method 3051 for digestion" and "Method 6010 for Chromium" in Test Method for Evaluation of Solid Wastes (SWA46), 3rd ed., Author, Washington, DC, 1990.

34. W. T. Elam, J. W. Adams, K. R. Hudson, B. McDonald, C. A. Weiss, J. C. Morgan and J. V. Gilfrich, "Subsurface Measurement of Soil Heavy Metal Concentrations with the SCAPS X-ray Fluorescence (XRF) Metals Sensor" Field Anal. Chem. Technol., to be published.

35. K. Y. Yamamoto, D. A. Cremers, M. J. Ferris and L. E. Foster, "Detection of Metals in the Environment Using a Portable Laser-Induced Breakdown Spectroscopy Instrument" Appl. Spectrosc. 50, 222-233, (1996). 